\title{
Age and time trends of dairy intake among children and adolescents of the DONALD study
}

\author{
Eva Hohoff ${ }^{1}$ (I) $\cdot$ Ines Perrar $^{1} \cdot$ Nicole Jancovic $^{1} \cdot$ Ute Alexy $^{1}$
}

Received: 1 October 2020 / Accepted: 3 April 2021 / Published online: 21 April 2021

(c) The Author(s) 2021

\begin{abstract}
Purpose To describe age and time trends in dietary intake of Total Dairy (TD) (g/1000 kcal Total Energy Intake) and types of dairy (weight percent of total dairy intake, w\%TD) represented as Low Fat Dairy (LFD), High Sugar Dairy (HSD), Fermented Dairy (FD) and Liquid Dairy (LD) among children and adolescents in Germany.

Methods Overall, 10,333 3-day dietary records kept between 1985 and 2019 by 1275 DONALD participants (3.5-18.5 years; boys: $50.8 \%$ ) were analyzed using polynomial mixed-effects regression models.

Results TD intake decreased with age ( $\sigma^{\lambda}$ : linear trend $p<0.0001$; $ᄋ$ : linear and quadratic trend $\left.p<0.0001\right)$, whereas FD ( $\left(+\right.$ : linear, quadratic, cubic trend $p \leq 0.02$ ) increased slightly in girls. HSD ( $\delta^{\lambda}$ : linear, quadratic, cubic trend $p \leq 0.004$; $ᄋ$ : linear, quadratic, cubic trend $p \leq 0.005$ ) and LD (linear, quadratic trend $p \leq 0.0002$ ) decreased with age. In terms of time trends, TD intake decreased in the last three decades, especially since 1995 (quadratic trend for ${ }^{\lambda} 0.0007$ and $q p=0.004$ ). LFD intake increased until 2010 and decreased thereafter (linear, quadratic, cubic trend $p<0.0001$ ). HSD decreased until 1995, then increased until 2010 and decreased again afterwards ( $\delta$ : linear, quadratic, cubic trend $p \leq 0.001$; $q$ : linear, quadratic, cubic trend $p \leq 0.003$ ). While FD intake increased linear (in both $\sigma^{\lambda}$ and $q: p<0.0001$ ), LD intake decreased (linear, quadratic trend $p \leq 0.03$ ).

Conclusion Our results showed changes in dairy consumption patterns among children and adolescents over the past three decades, demonstrating a decrease in TD intake with age and time, and a shift from liquid to solid dairy products with a simultaneous increase in fermented dairy products, while LFD and HSD fluctuated over time. Further evaluations will examine the health significance of these consumption patterns.
\end{abstract}

Keywords Dairy $\cdot$ Dairy intake $\cdot$ Time trends $\cdot$ Age trends $\cdot$ Children $\cdot$ Adolescents

\section{Introduction}

In recent years, several meta-analyses examined associations between dairy consumption and health outcomes. A current meta-analysis of prospective cohort studies in children

Ute Alexy

alexy@uni-bonn.de

Eva Hohoff

ehohoff@uni-bonn.de

Ines Perrar

iperrar@uni-bonn.de

Nicole Jancovic

njankovic@uni-bonn.de

1 Department of Nutritional and Food Sciences, Nutritional Epidemiology, University of Bonn, DONALD Study Dortmund, Heinstück 11, 44225 Dortmund, Germany indicated an inverse relationship between total dairy intake and body fat ratio as well as the risk of overweight/obesity [1]. Further meta-analyses of intervention trials and observational studies found a positive association of dairy related to bone mineral content in children [2] and an inverse relationship between dairy intake and diabetes mellitus 2 [3].

However, dairy is a heterogeneous food group in terms of nutrient content and differs mainly in fat and added sugar content. The relevance of nutrient contents was shown in three meta-analyses of observational studies showing an inverse association between the amount of dairy consumption and diabetes type 2 risk only for fat reduced dairy products [4-6]. Since dairy products contribute to a large extent (12\%) to the intake of free sugar among children and adolescents [7], sugar content of dairy should also be of interest.

Furthermore, processing methods may enhance interactions between nutrients in dairy, which may modify the 
metabolic effects of dairy consumption [8]. A number of studies have attributed a protective effect against various diseases such as diabetes type 2 to fermented dairy [4, 9]. In the European Prospective Investigation into Cancer and Nutrition (EPIC) study as well as in the National Health and Nutrition Examination Survey (NHANES) study, the consumption of yogurt was also associated with a reduced weight gain $[9,10]$. Furthermore, the consistency of dairy products, i.e., liquid or solid, may also be relevant, since liquid foods are discussed to have a less satiation impact than solid foods [11, 12].

Since dairy intake in childhood was associated with healthy eating patterns and lifestyle factors in adults [13], age and time trends in dairy intake as well as in the intake of different types of dairy among children and adolescence are of particular interest. In a previous dairy trend analysis with healthy subjects of the German DONALD (DOrtmund Nutritional and Anthropometric Longitudinally Designed) study from 1986 to 2001 total consumption of dairy products remained at least stable over 4 years, but a shift from dairy beverages towards dairy foods was observed. In children and adolescents, dietary habits change with age, e.g., during puberty [14]. This is important considering the fact that puberty may be a critical period for the development of overweight [15].

However, in the last 20 years, new products and increasingly dairy alternatives were introduced. Therefore, the aim of the present analyses was to examine current age and time trends in the intake of dairy and dairy types among 3.5to 18.5-year-old DONALD participants over three decades from 1985 to 2019.

\section{Methods}

\section{Study sample}

The DONALD study is an ongoing open cohort study collecting information on nutrition, growth, development and metabolism of children and adolescents in Dortmund, Germany. Since 1985, the study has enrolled approximately 35-40 healthy infants each year. Annual examinations include 3-day weighing protocols, anthropometric measurements, medical examinations, lifestyle interviews, and 24-h urine samples. Parental examinations occur every 4 years. Further details of the study are described elsewhere [16, 17].

The study is approved by the ethics committee of the University of Bonn according to the guidelines of the Declaration of Helsinki. At the beginning of the present analysis (June 2019), a total of 17,782 records was available. Records were excluded if they were incomplete $(<3$ days, $n=192)$ or if they were from $<3.5$-year-olds $(n=20,700)$ or $>18.5$-year-olds $(n=1491)$. Records with intake of breast milk or formula were also eliminated $(n=156)$. Hence, for the present evaluation, we analyzed 10,333 complete dietary records from 1275 DONALD study participants $(n=648$ boys, 627 girls).

\section{Dietary assessment}

In the DONALD study, dietary intake is recorded on the basis of 3-day weighed dietary records. The food and beverages consumed, as well as leftovers, are weighed and recorded by parents or by the older participants themselves using electronic food scales. Semi-quantitative recording (e.g., spoons, cups) is allowed, if accurate weighing is not possible. Information on recipes (ingredients and preparation) and on the types and brands of commercial food products is also required. Medication and dietary supplement use were excluded for the present analyses. Energy and nutrient intake are calculated using the continually updated in-house food composition database LEBTAB [18]. The composition of basic foods is based on the German food composition tables BLS 3.02. Energy and nutrient contents of commercial food products, i.e., canned foods, ready to eat meals or snacks, are estimated by recipe simulation using labeled ingredients and nutrient contents [18].

\section{Definitions of outcome variables}

In the current analyses, total dairy and different types of dairy were examined as outcome variables (Table 1). Total Dairy (TD) was defined as all dairy products (Table 1) and calculated in g/1000 kcal Total Energy Intake (TEI) per day. In addition, dairy products were further subdivided into the following in part overlapping dairy types. In terms of nutrient content, we specified Low Fat Dairy (LFD) compared to high-fat dairy and High Sugar Dairy (HSD) compared to low sugar dairy (Table 1). According to fermentation status, we defined Fermented Dairy (FD) compared to nonfermented dairy. Finally, Liquid Dairy (LD) was defined as dairy consumed as a beverage versus food dairy that was eaten (Table 1). All types of dairy were calculated as weight percent of TD intake (w\%TD).

For simplicity, only the four dairy types LFD, HSD, FD and LD are presented below, since they correspond to each other anyway with their respective pairs of opposites with reversed signs.

\section{Assessment of potential confounding factors}

The following variables were taken into consideration as potential confounding factors: sex (boy/girl), body weight status (normal weight, overweight, obesity, underweight), number of weekdays per 3-day record (1/2/3), maternal overweight status (normal weight, overweight, obesity), high 
Table 1 Food group classification of dairy products ${ }^{\mathrm{a}}$, DONALD study

\begin{tabular}{|c|c|}
\hline Classified food group & Foods \\
\hline Total dairy (TD) & $\begin{array}{l}\text { All dairy products (including dairy from cows and other mammals, such as goats or sheep), excluding cream cakes } \\
\text { and ice cream, because they are consumed as sweets rather than to meet dairy requirements, and excluding butter }\end{array}$ \\
\hline Liquid dairy (LD) & $\begin{array}{l}\text { Fresh milk, not-fermented and fermented drinks (e.g., cacao, buttermilk, whey), liquid sour milk products (incl. } \\
\text { squeeze sour milk), yogurt drink }\end{array}$ \\
\hline Fermented dairy (FD) & $\begin{array}{l}\text { Fermented liquid and solid dairy: fermented dairy drinks (buttermilk, whey), liquid sour milk products (incl. } \\
\text { squeeze sour milk), yogurt drink, yogurt, firm sour milk products, fermented desserts, fresh cheese, quark, cream } \\
\text { fraiche, cheese (soft cheese, sliced cheese, hard cheese, and processed cheese) }\end{array}$ \\
\hline Low fat dairy ${ }^{\mathrm{b}}$ (LFD) & $\begin{array}{l}\text { Non-fermented and fermented beverage dairy, non-fermented solid dairy, fermented solid dairy (fresh cheese, } \\
\text { quark })<2 \% \text { fat, fresh cheese, quark ( }<9 \% \text { fat }) \text {, soft cheese, processed cheese }(<15 \% \text { fat }) \text {, semi-hard and hard } \\
\text { cheese }(<18 \% \text { fat) }\end{array}$ \\
\hline High sugar dairy ${ }^{\mathrm{c}, \mathrm{d}}(\mathrm{HSD})$ & Added sugar $>7 \mathrm{~g} / 100 \mathrm{~g}$ industrially sweetened dairy \\
\hline
\end{tabular}

${ }^{\text {a }}$ Dairy products can occur in different groups

${ }^{\mathrm{b}}$ Classification based on https://www.lebensmittellexikon.de/f0000170.php

${ }^{\mathrm{c}}$ Including instant powders for milk (i.e., cocoa)

${ }^{\mathrm{d}}$ Defined by the 1 st quartile $(6.9 \mathrm{~g})$ added sugar/100 $\mathrm{g}$ in the 965 sweetened products reported by the study sample

maternal educational status (yes/no), and maternal employment (yes/no).

Weight and height of the participants were measured by study nurses according to standard procedures [16], dressed only in underwear and barefoot using an electronic scale (Seca 753E; Seca Weighing and Measuring System, $\pm 100 \mathrm{~g}$ ) and a digital stadiometer (Harpenden, Crymych, UK, $\pm 0.1 \mathrm{~cm}$ ). Body mass index (BMI $\left[\mathrm{kg} / \mathrm{m}^{2}\right]$ ) was calculated as the body weight $(\mathrm{kg})$ divided by the square of the body height $\left(\mathrm{m}^{2}\right)$. Overweight was determined corresponding to International Obesity Task Force's (IOTF) BMI cutoff values for children and adolescents $[19,20]$. Maternal overweight was defined as a BMI $\geq 25$ to $<30 \mathrm{~kg} / \mathrm{m}^{2}$, maternal obesity as a BMI $>30 \mathrm{~kg} / \mathrm{m}^{2}$.

High maternal educational status ( $\geq 12$ school years) and maternal employment are surveyed using a standardized questionnaire. Missing values were replaced by the respective median of the total sample $(n=127$ for maternal overweight, $n=16$ for maternal educational status).

\section{Statistical analysis}

All statistical analyses were carried out using SAS ${ }^{\circledR}$ procedures (version 9.20 and 9.40; Cary, NC, USA). The significance level was set at $p<0.05$. Descriptive data are shown as median with their interquartile range or frequencies and percentages. We stratified the data for descriptive purpose according to the following age groups: $3.5<6.5$ years $(n=8256), 6.5<10.5$ years $(n=9588), 10.5<14.5$ years $(n=7587)$ and $14.5 \leq 18.5$ years $(n=5568)$ (Table 2$)$ and to the following time periods: 1985-1989, 1990-1994, 1995-1999, 2000-2004, 2005-2009, 2010-2014, 2015-2019) (Supplemental Table 1).
Age and time trends in TD (g/1000 kcal TEI), LFD, HSD, $\mathrm{FD}$, and $\mathrm{LD}(\mathrm{w} \%)$ were analyzed using polynomial regression models (PROC MIXED procedure in SAS) including both fixed and random statements.

A basic model was calculated for all variables, which included time in years (baseline was the first record included in the evaluation) and chronological age (years) as the most important fixed effects. Quadratic and cubic terms of age $\left(\mathrm{age}^{2}, \mathrm{age}^{3}\right)$ and time $\left(\mathrm{time}^{2}, \mathrm{time}^{3}\right)$ were considered as additional explanatory variables if they significantly predicted the respective outcome or improved the fit statistics [Akaike information criterion (AIC)] by more than two points [21]. There were no interactions between age and time (age $\times$ time) in all models.

A significant linear trend reflects a constant increase or decrease in the respective outcome variable over the years or with age. In contrast, quadratic and cubic trends indicate that the size of the trend changes over the study period or with age. A stratified analysis was conducted for significant sex interactions (sex $\times$ age, sex $\times$ time).

A repeated statement was considered so as to account for the lack of independence between repeated measures from the same person. Random effects were considered to allow variation between individuals and families with respect to the initial level (intercept) as well as linear, quadratic and cubic age trends of the respective outcome. The AIC was also used to select the covariance structure that best described the variances and covariances of the initial level, the linear and quadratic trend among persons, and the covariance structure that best describes the correlated nature of the repeated measurements. The variables remained in the final models if they had a significant and independent association with the outcome variable $(p<0.05)$, if the regression 
Table 2 Sample and dietary characteristics of $n=10,333$ 3-day-weighted dietary records of $n=1275$ DONALD (boys $n=648$, girls $n=627$ ) participants aged 3.5-18.5 years, collected between 1985 and June 2019, stratified by sex and age groups, DONALD study

\begin{tabular}{|c|c|c|c|c|c|c|c|c|}
\hline & \multicolumn{4}{|l|}{ Boys } & \multicolumn{4}{|l|}{ Girls } \\
\hline & $3.5<6.5$ & $6.5<10.5$ & $10.5<14.5$ & $14.5 \leq 18.5$ & $3.5<6.5$ & $6.5<10.5$ & $10.5<14.5$ & $14.5 \leq 18.5$ \\
\hline$n_{\text {participants }}{ }^{\mathrm{a}}$ & 556 & 505 & 407 & 294 & 539 & 471 & 376 & 289 \\
\hline $\begin{array}{l}n_{3 \text {-day-dietary-records }} \\
(\%)\end{array}$ & $1392(26)$ & $1644(31)$ & $1300(25)$ & $943(18)$ & $1360(27)$ & $1552(31)$ & $1229(24)$ & $913(18)$ \\
\hline Age (years) & $5.0(4.1 ; 6.0)$ & $8.2(7.2 ; 9.2)$ & $\begin{array}{l}12.2(11.2 \\
13.2)\end{array}$ & $\begin{array}{l}16.2(15.2 ; \\
17.2)\end{array}$ & $5.0(4.1 ; 6.0)$ & $8.2(7.3 ; 9.2)$ & $\begin{array}{l}12.2(11.2 ; \\
13.2)\end{array}$ & $\begin{array}{l}11.2(15.2 ; \\
17.3)\end{array}$ \\
\hline $\begin{array}{l}\text { Underreported } \\
\text { records }\end{array}$ & $34(2.4)$ & $65(4.0)$ & $169(13.0)$ & $215(22.8)$ & $36(2.7)$ & $30(1.9)$ & $104(8.5)$ & $195(21.4)$ \\
\hline \multicolumn{9}{|l|}{ Anthropometrics } \\
\hline BMI & $\begin{array}{l}15.6(14.9 ; \\
16.4)\end{array}$ & $\begin{array}{l}15.6(14.8 ; \\
16.7)\end{array}$ & $\begin{array}{l}17.7(16.1 ; \\
19.5)\end{array}$ & $\begin{array}{l}20.4(18.5 ; \\
22.9)\end{array}$ & $\begin{array}{l}15.5 \\
16.4)\end{array}$ & $\begin{array}{l}15.5(14.7 ; \\
16.9)\end{array}$ & $\begin{array}{l}17.3(16.0 ; \\
19.6)\end{array}$ & $\begin{array}{l}20.5(18.8 ; \\
22.7)\end{array}$ \\
\hline Normal weight & $452(81.3)$ & $415(82.2)$ & $312(76.7)$ & $215(73.1)$ & $421(78.1)$ & $345(73.3)$ & $279(74.2)$ & $219(75.8)$ \\
\hline Overweight & $32(5.8)$ & $38(7.5)$ & $55(13.5)$ & $49(16.7)$ & $55(10.2)$ & $59(12.5)$ & $52(13.8)$ & $33(11.4)$ \\
\hline Obesity & $3(0.5)$ & $10(2.0)$ & $9(2.1)$ & $11(3.7)$ & $5(0.9)$ & $5(1.1)$ & $5(1.3)$ & $5(1.7)$ \\
\hline Underweight $^{\mathrm{b}}$ & $69(12.4)$ & $42(8.3)$ & $31(7.6)$ & $19(6.5)$ & $58(10.8)$ & $62(13.2)$ & $40(10.6)$ & $32(11.1)$ \\
\hline \multicolumn{9}{|c|}{ Maternal characteristics } \\
\hline Normal weight & $376(68.7)$ & $341(68.9)$ & $259(64.8)$ & $173(60.1)$ & $366(69.2)$ & $312(67.1)$ & $224(60.2)$ & $174(60.8)$ \\
\hline Overweight & $127(23.2)$ & $115(23.2)$ & $107(26.8)$ & $85(29.5)$ & $123(23.3)$ & $121(26.0)$ & $113(30.4)$ & $82(28.7)$ \\
\hline Obesity & $44(8.0)$ & $39(7.9)$ & $34(8.5)$ & $30(10.4)$ & $40(7.6)$ & $32(6.9)$ & $35(9.4)$ & $30(10.5)$ \\
\hline $\begin{array}{l}\text { High educa- } \\
\text { tional status }\end{array}$ & 387 (69.6) & $321(63.7)$ & $241(59.4)$ & $174(59.2)$ & $353(65.6)$ & $294(62.4)$ & $222(59.4)$ & $171(59.4)$ \\
\hline Employment & $243(43.7)$ & $296(58.6)$ & $269(66.1)$ & $213(72.5)$ & $238(44.2)$ & $260(55.2)$ & $246(65.4)$ & $196(67.8)$ \\
\hline \multicolumn{9}{|c|}{ Dietary characteristics } \\
\hline TEI (kcal/day) & $\begin{array}{l}1353(1195 \\
1520)\end{array}$ & $\begin{array}{l}1720(1518 \\
1922)\end{array}$ & $\begin{array}{l}2010(1742 \\
2310)\end{array}$ & $\begin{array}{l}2439(2083 \\
2810)\end{array}$ & $\begin{array}{l}1235(1094 \\
1384)\end{array}$ & $\begin{array}{l}1545(1356 ; \\
1720)\end{array}$ & $\begin{array}{l}1772(1525 ; \\
2021)\end{array}$ & $\begin{array}{l}\text { 1778 (1503; } \\
2054)\end{array}$ \\
\hline $\begin{array}{l}\text { TD } \\
(\mathrm{g} / 1000 \mathrm{kcal} \\
\text { of TEI })\end{array}$ & $213(142 ; 293)$ & $191(124 ; 275)$ & $170(100 ; 246)$ & $151(92 ; 223)$ & $204(132 ; 280)$ & $174(113 ; 247)$ & $151(93 ; 215)$ & $143(81 ; 215)$ \\
\hline LFD (w\%TD) & $\begin{array}{l}15.1(1.5 ; \\
60.0)\end{array}$ & $\begin{array}{l}16.8(1.1 ; \\
60.5)\end{array}$ & $\begin{array}{l}24.4(1.4 ; \\
72.0)\end{array}$ & $\begin{array}{l}28.4(1.5 ; \\
75.8)\end{array}$ & $\begin{array}{l}18.0(1.6 \\
62.5)\end{array}$ & $\begin{array}{l}21.1(1.5 ; \\
62.9)\end{array}$ & $\begin{array}{l}27.5(1.3 ; \\
72.0)\end{array}$ & $34.0(0.9 ; 72.8)$ \\
\hline HSD (w\%TD) & $\begin{array}{l}28.9(12.2 ; \\
52.3)\end{array}$ & $\begin{array}{l}24.1(9.1 ; \\
46.5)\end{array}$ & $\begin{array}{l}24.1(8.5 ; \\
48.3)\end{array}$ & $\begin{array}{l}18.9(6.0 \\
41.5)\end{array}$ & $\begin{array}{l}31.9 \\
59.1)\end{array}$ & $\begin{array}{l}29.6(12.8 ; \\
53.9)\end{array}$ & $\begin{array}{l}31.1(13.0 ; \\
56.0)\end{array}$ & $\begin{array}{l}27.6(11.2 ; \\
50.8)\end{array}$ \\
\hline FD (w\%TD) & $\begin{array}{l}20.3(7.8 \\
41.3)\end{array}$ & $\begin{array}{l}20.0(7.9 ; \\
40.5)\end{array}$ & $\begin{array}{l}23.6(9.7 \text {; } \\
46.4)\end{array}$ & $\begin{array}{l}25.5(10.2 ; \\
48.2)\end{array}$ & $\begin{array}{l}22.0(8.7 ; \\
41.1)\end{array}$ & $\begin{array}{l}22.0(9.0 \\
42.2)\end{array}$ & $\begin{array}{l}27.8(11.3 ; \\
51.7)\end{array}$ & $\begin{array}{l}32.4(16.1 ; \\
58.9)\end{array}$ \\
\hline LD (w\%TD) & $\begin{array}{l}56.6(29.4 ; \\
75.9)\end{array}$ & $\begin{array}{l}52.2(20.7 ; \\
73.1)\end{array}$ & $\begin{array}{l}43.4(0.0 \\
68.0)\end{array}$ & $\begin{array}{l}40.4(0.0 \\
67.2)\end{array}$ & $\begin{array}{l}55.2(27.3 ; \\
76.5)\end{array}$ & $\begin{array}{l}51.2(22.8 \\
72.3)\end{array}$ & $\begin{array}{l}40.8(0.0 \\
65.8)\end{array}$ & $34.6(0.0 ; 63.4)$ \\
\hline
\end{tabular}

Values are $n(\%)$ or medians (25th, 75th percentile)

$T E I$ total energy intake; $T D$ total dairy; $L F D$ low fat dairy; $H S D$ high sugar dairy; $F D$ fermented dairy; $L D$ liquid dairy; $w \% T D$ intake weight as $\%$ of total dairy

${ }^{a}$ Due to repeated measurements per participant. One person can occur in more than one age group

${ }^{\mathrm{b}}$ IOTF Criteria

c > 12 years school education

coefficients in the basic models were modified by $\geq 10 \%$ or if they led to an improvement in AIC of more than two points.

As single effect estimates of polynomial models cannot be interpreted, figures show the predicted trends for TD, LFD, HSD, FD, and LD resulting from the polynomial mixedeffects regression models over the course of the study period for different ages. Thus, the course of the curves illustrates the time trend and the vertical differences between the curves of the different ages indicate the age trend.

To avoid possible bias in the results, sensitivity analyses were run excluding records defined as underreported. Records were classified as underreported when the TEI was inadequate in relation to the estimated basal metabolic rate (BMR) according to age- and sex-specific equations 
of Schofield [22]. Pediatric cutoffs from Sichert-Hellert et al. [23] were used to identify underreported records. This calculation resulted in $848(8.21 \%)$ underreported records (Table 2). Underreported records were not excluded from the main analyses, as this method only identifies underreported energy intake, but not selective underreporting of food groups [24]. Furthermore, participants with high-energy requirements (e.g., high physical activity), who may have been underreported, could not be identified [25]. Sensitivity analyses excluding the underreported datasets showed similar results in time and age trends.

\section{Results}

The sample of the present evaluation includes all available complete dietary records $(n=10,033)$ of $n=1275$ participants ( $n=648$, boys $50.82 \%$ ) aged $3.5-18.5$ years collected between August 1985 and June 2019. Per participant, a minimum of $1(n=144 ; 11.3 \%)$ to a maximum of $15(n=207 ; 16.2 \%)$ dietary records [median (Q1; Q3): 8 (5; 12)] were available.

Sample characteristics are shown in Table 2. About half of the participants were female. The overweight status and maternal characteristics of the participants reflect the high socio-economic status of the DONALD study participants.

Dietary characteristics stratified by age groups and sex are also displayed in Table 2. Intake of dairy and dairy types stratified by time periods and sex are presented in supplemental Table 1 . The results of age and time trend analyses are presented in Table 3 and in Figs. 1-5.

\section{Total dairy}

TD intake decreased with age in boys and girls $\left(\delta^{\lambda}\right.$ : linear trend $p<0.0001$; : : linear and quadratic trend $p<0.0001$ ), but for girls the intake is about the same among the 12-18-year-olds (Fig. 1). In terms of time trends, TD intake increased slightly for boys until 1995 and then decreased thereafter until the end of the analysis period. For girls, the intake of TD was at a similar level between 1985 and 1995 and decreased since 1995 (quadratic trend $\widehat{\partial}: p=0.0007$ and o : $p=0.0044)$ (Fig. 1).

\section{Dairy types}

LFD intake was almost at a comparable level among the age groups (quadratic trend $p=0.0267$, cubic trend $p=0.0177$ ). The time trend analysis of LFD showed a slightly decrease between 1985 and 1990, a sharply increase since 1990 and finally in a strong decrease since 2010 (linear, quadratic, cubic trend $p<0.0001$ ) (Fig. 2).
The age trend analysis of HSD showed the highest HSD intake in the youngest and the lowest intake in the oldest age group in both, boys and girls $\left(\sigma^{\lambda}\right.$ : linear trend $p=0.0028$, quadratic trend $p=0.0035$, cubic trend $p=0.0029$; ㅇ: linear trend $p=0.0049$, quadratic trend $p=0.0032$, cubic trend $p=0.0014)$. Differences between the other age groups were negligible. In terms of time trends, HSD intake decreased between 1985 and 1995 in both sexes, increased in girls until 2010 and in boys until 2015 and decreased again afterwards in both sexes $(\hat{O}$ : linear trend $p=0.0013$, quadratic trend $p=0.0001$, cubic trend $p=0.0002$; $q$ : linear trend $p=0.0033$, quadratic trend $p=0.0004$, cubic trend $p=0.0002$ ) (Fig. 3).

FD intake did not differ much between the age groups for boys. For girls there was a slight age trend with the highest intake in the oldest and the lowest intake in the youngest age group ( $\sigma^{\lambda}$ : linear trend $p=0.0192$; . : linear trend $p=0.0248$, quadratic trend $p=0.0040$, cubic trend $p=0.0041)$. FD intake increased almost linear throughout the 30-year study period ( $\delta$ and + : linear trend $p<0.0001$ ) (Fig. 4).

LD intake decreased slightly with age among the 16-18-year-olds, and it did not differ much (linear trend $p<0.0001$, quadratic trend $p=0.0002$ ). The time trend analyses in LD intake showed an almost linear decrease between 1985 and 2019 (linear trend $p<0.0001$, quadratic trend $p=0.0329$ ) (Fig. 5).

\section{Discussion}

Based on a unique and comprehensive longitudinal database, the present study identified age and time trends in the intake of TD and as a first for its types (LFD, HSD, FD and LD) among children and adolescents in Germany between 1985 and 2019.

TD intake (g/1000 kcal TEI) decreased with age and time. The observed time trend is in line with the findings of the review by Dror et al. showing a decline of dairy consumption among children and adolescents in developed countries over the past three decades [26]. In addition, the current results of the European IDEFICS (Identification and prevention of Dietary- and lifestyle-induced health Effects In Children and infantS) study suggests a decline of dairy intake between 2007/2008 and 2013/2014, most notably at snack bar events [27].

As meta-analyses with children [1,2] showed health benefits of dairy intake, the observed decrease in TD appears to be critical. However, it is not yet clear how much dairy should be consumed by children and adolescents. While some European countries, such as the Nordic countries and Spain, do not provide quantitative but only qualitative recommendations for dairy intake, most countries generally recommend two to three servings daily [28]. The German 
Table 3 Age and time trends in dairy intake of $n=10,333$ dietary records of $n=1275$ DONALD participants, aged 3.5-18.5 years, collected between 1985 and 2019

\begin{tabular}{|c|c|c|c|c|c|c|}
\hline & \multicolumn{3}{|c|}{ Age trend per year of age (3.5-18.5 years $)^{\mathrm{a}}$} & \multicolumn{3}{|c|}{ Time trend per study year $(1985-2019)^{\mathrm{b}}$} \\
\hline & Age & $\mathrm{Age}^{2}$ & $\mathrm{Age}^{3}$ & Time & Time $^{2}$ & Time $^{3}$ \\
\hline & ß $(p)$ & $ß(p)$ & $ß(p)$ & $\beta(p)$ & $\beta(p)$ & $\beta(p)$ \\
\hline \multicolumn{7}{|c|}{ Total dairy (g/1000 kcal TEI) } \\
\hline \multicolumn{7}{|c|}{ Boys $^{c}$} \\
\hline $\begin{array}{l}\text { Unadjusted } \\
\text { model }\end{array}$ & $\begin{array}{r}-4.5844 \\
(<0.0001)\end{array}$ & & & $0.6491(0.5021)^{\prime}$ & \multicolumn{2}{|l|}{$-0.08839(0.0006)^{\prime}$} \\
\hline Adjusted model & $\begin{array}{c}-4.5746 \\
(<\mathbf{0 . 0 0 0 1})\end{array}$ & & & 0.3909 (0.6899) & \multicolumn{2}{|l|}{$-0.08737(\mathbf{0 . 0 0 0 7})$} \\
\hline \multicolumn{7}{|l|}{ Girls $^{\mathrm{d}}$} \\
\hline $\begin{array}{l}\text { Unadjusted } \\
\text { model }\end{array}$ & $\begin{array}{l}-16.4255 \\
(<0.0001)\end{array}$ & \multicolumn{2}{|l|}{$0.5383(<0.0001)$} & $0.7199(0.4599)^{\prime}$ & \multicolumn{2}{|l|}{$-0.07368(0.0041)^{\prime}$} \\
\hline Adjusted model & $\begin{array}{l}-16.7772 \\
(<\mathbf{0 . 0 0 0 1})\end{array}$ & \multicolumn{2}{|l|}{$0.5411(<\mathbf{0 . 0 0 0 1})$} & $0.7893(0.4087)$ & \multicolumn{2}{|l|}{$-0.07306(\mathbf{0 . 0 0 4 4 )}$} \\
\hline \multicolumn{7}{|c|}{ Low fat dairy $(w \% T D)^{\mathrm{h}}$} \\
\hline $\begin{array}{l}\text { Unadjusted } \\
\text { model }\end{array}$ & $-3.1081(0.0233)$ & $0.3424(0.0114)^{\prime}$ & $-0.01094(0.0085)$ & $-1.7281(0.0002)$ & $0.2667(<0.0001)^{\prime}$ & $\begin{array}{l}-0.00609 \\
(<0.0001)\end{array}$ \\
\hline Adjusted model & $-2.4395(0.0773)$ & 0.3009 (0.0267)' & -0.00989 (0.0177) & $\begin{array}{l}-1.8235 \\
(<\mathbf{0 . 0 0 0 1})\end{array}$ & $0.2706(<\mathbf{0 . 0 0 0 1})$ & $\begin{array}{l}-0.00615 \\
(<\mathbf{0 . 0 0 0 1})\end{array}$ \\
\hline \multicolumn{7}{|c|}{ High sugar dairy (w \%TD) } \\
\hline \multicolumn{7}{|c|}{ Boys $^{\mathrm{i}}$} \\
\hline $\begin{array}{l}\text { Unadjusted } \\
\text { model }\end{array}$ & $-5.9030(0.0009)$ & $0.5367(0.0022)$ & $-0.01660(0.0020)^{\prime}$ & $-1.8524(0.0007)$ & $0.1302(0.0002)$ & $-0.00235(0.0004)$ \\
\hline Adjusted model & -5.2977 (0.0028) & 0.5114 (0.0035)' & $-0.01600(\mathbf{0 . 0 0 2 9})$ & $-1.7557(\mathbf{0 . 0 0 1 3})$ & 0.1346 (0.0001) & -0.00247 (0.0002)' \\
\hline \multicolumn{7}{|l|}{ Girls $^{\mathrm{j}}$} \\
\hline $\begin{array}{l}\text { Unadjusted } \\
\text { model }\end{array}$ & $-5.4697(0.0040)$ & $0.5581(0.0029)$ & $-0.01851(0.0013)$ & $-1.6730(0.0035)$ & $0.1324(0.0004)^{\prime}$ & $-0.00263(0.0002)^{\prime}$ \\
\hline Adjusted model & -5.3363 (0.0049)' & 0.5517 (0.0032)' & -0.01834 (0.0014) & $-1.6804(\mathbf{0 . 0 0 3 3})$ & 0.1318 (0.0004)' & -0.00262 (0.0002)' \\
\hline \multicolumn{7}{|c|}{ Fermented dairy (w\%TD) } \\
\hline \multicolumn{7}{|c|}{ Boys $^{\mathrm{f}}$} \\
\hline $\begin{array}{l}\text { Unadjusted } \\
\text { model }\end{array}$ & $0.2497(0.0413)^{\prime}$ & & & $0.5855(<0.0001)^{\prime}$ & & \\
\hline Adjusted model & 0.3594 (0.0192) & & & $0.5800(<\mathbf{0 . 0 0 0 1})^{\prime}$ & & \\
\hline \multicolumn{7}{|l|}{ Girls $^{\mathrm{g}}$} \\
\hline $\begin{array}{l}\text { Unadjusted } \\
\text { model }\end{array}$ & $-4.7073(0.0066)$ & $0.5148(0.0028)$ & $-0.01486(0.0050)^{\prime}$ & $0.5058(<0.0001)$ & & \\
\hline Adjusted model & -3.9043 (0.0248) & 0.4955 (0.0040)' & $-0.01517(\mathbf{0 . 0 0 4 1})$ & $0.5013(<\mathbf{0 . 0 0 0 1})$ & & \\
\hline \multicolumn{7}{|c|}{ Liquid dairy $(w \% T D)^{\mathrm{e}}$} \\
\hline $\begin{array}{l}\text { Unadjusted } \\
\text { model }\end{array}$ & $\begin{array}{c}-2.4665 \\
(<0.0001)\end{array}$ & $0.06682(0.0010)^{\prime}$ & & $\begin{array}{l}-1.1254 \\
(<0.0001)\end{array}$ & $0.01157(0.0353)^{\prime}$ & \\
\hline Adjusted model & $\begin{array}{c}-2.8791 \\
(<\mathbf{0 . 0 0 0 1})\end{array}$ & 0.07708 (0.0002) & & $\begin{array}{l}-1.1428 \\
(<\mathbf{0 . 0 0 0 1})\end{array}$ & $0.01170(\mathbf{0 . 0 3 2 9})$ & \\
\hline
\end{tabular}

Significant $p$-values in the adjusted model are bolded

$w \% T D$ intake weight as \% of TD; TEI total energy intake (kcal/day)

Age and time trends were tested using polynomial mixed-effect regression models

${ }^{a}$ Age $=$ linear age trend, age $^{2}=$ quadratic age trend, age ${ }^{3}=$ cubic age trend

${ }^{\mathrm{b}}$ Time $=$ linear time trend, time ${ }^{2}=$ quadratic time trend, time ${ }^{3}=$ cubic time trend

${ }^{c}$ Model contains a random statement for the family level with an unstructured covariance structure and a random statement for the person level with an unstructured covariance structure adjusted for number of weekdays per record (1/2/3), high maternal educational status (yes/no), maternal overweight status (normal weight, overweight, obesity)

${ }^{\mathrm{d}}$ Model contains a random statement for the family level with an unstructured covariance structure and a random statement for the person level with a Huynh-Feldt covariance structure adjusted for number of weekdays per record (1/2/3) 
Table 3 (continued)

${ }^{\mathrm{e}}$ Model contains a random statement for the family level with an unstructured covariance structure and a random statement for the person level with a no diagonal factor analytic covariance structure adjusted for TEI and for number of weekdays per record (1/2/3)

${ }^{\mathrm{f}}$ Model contains a random statement for the family level with an unstructured covariance structure and a random statement for the person level with an unstructured covariance structure adjusted for TEI

${ }^{g}$ Model contains a random statement for the family level with a Huynh-Feldt covariance structure and a random statement for the person level with an unstructured covariance structure adjusted for TEI

${ }^{\mathrm{h}}$ Model contains a random statement for the family level with an unstructured covariance structure and a random statement for the person level with an unstructured covariance structure adjusted for TEI, overweight status (normal weight, overweight, obesity, and underweight), maternal overweight status (normal weight, overweight, obesity)

${ }^{\mathrm{i}}$ Model contains a random statement for the family level with an unstructured covariance structure and a random statement for the person level with an unstructured covariance structure adjusted for overweight status (normal weight, overweight, obesity, and underweight), TEI, high maternal educational status (yes/no)

${ }^{\mathrm{j}}$ Model contains a random statement for the family level with an unstructured covariance structure and a random statement for the person level with a no diagonal factor analytic covariance structure adjusted for number of weekdays per record (1/2/3)

${ }^{\mathrm{k}}$ Model contains a random statement for the family level with an unstructured covariance structure and a random statement for the person level with an unstructured covariance structure adjusted for number of weekdays per record (1/2/3) and overweight status (normal weight, overweight, obesity, and underweight)

${ }^{1}$ Model contains a random statement for the family level with a no diagonal factor analytic covariance structure and a random statement for the person level with a no diagonal factor analytic covariance structure adjusted for number of weekdays per record (1/2/3) and high maternal educational status (yes/no)

${ }^{m}$ Model contains a random statement for the family level with an unstructured covariance structure and a random statement for the person level with an unstructured covariance structure adjusted for number of weekdays per record $(1 / 2 / 3)$

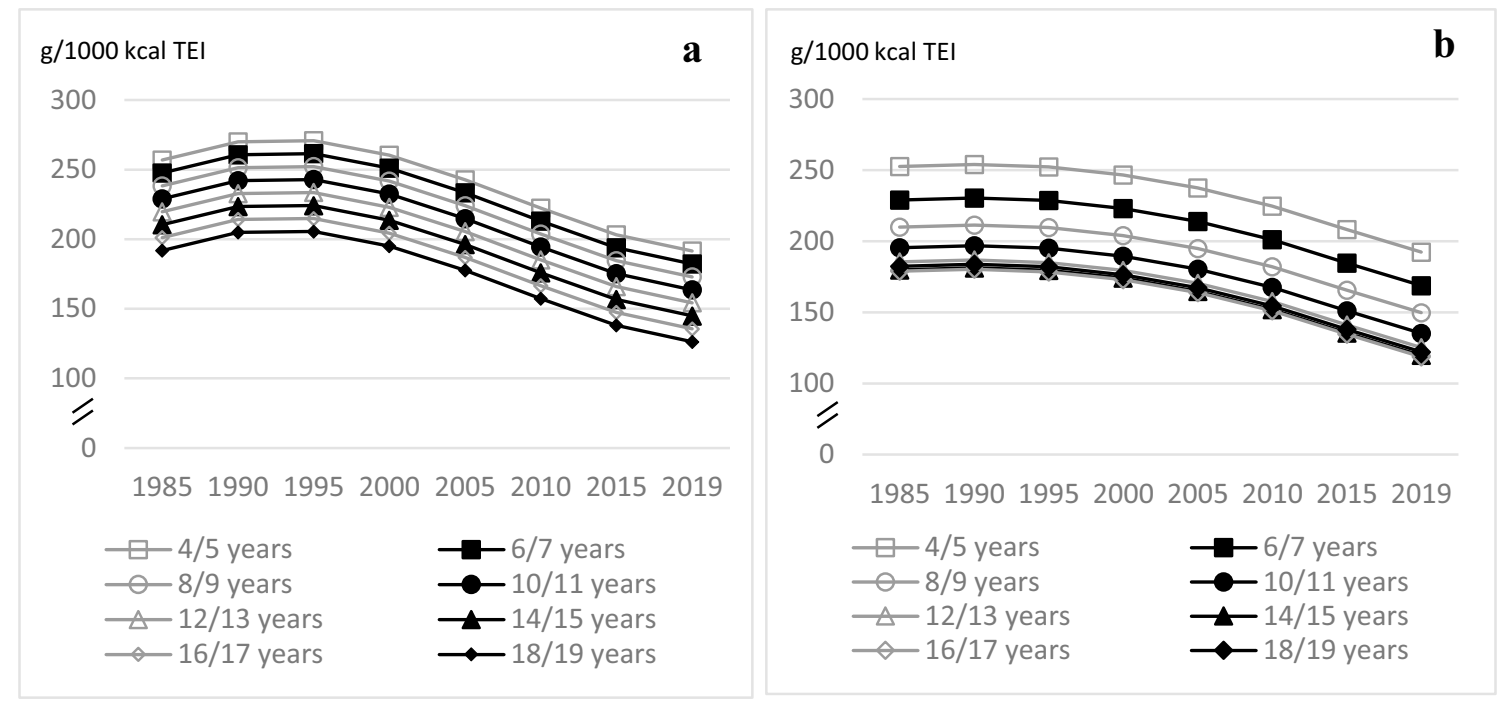

Fig. 1 Age and time trends in TD g/1000 kcal TEI in boys (a) and in girls (b) of 10,333 3-day-weighted dietary records of 648 male and 627 female DONALD study participants (3.5-18.5 years) between

dietary guidelines recommend a daily intake of about $260 \mathrm{~g} / 1000 \mathrm{kcal}$ corresponding to the three servings of dairy [29]. Median intake among DONALD participants in the current investigation was lower, in particular in older study participants. However, Canada's Food Guide as well as the newly developed EAT Lancet diet focus on plant protein, leaving a less prominent role for dairy products despite the importance of this food group on health [30,31]. However, evidence stems mainly from adult populations. In addition, recent research suggests that the total dairy approach may
1985 and 2019, predicted by polynomial mixed-effects regression models (see Table 3)

not be meaningful because different types of dairy may affect health in different ways $[38,52,53]$. Hence, further studies are necessary about the impact of dairy intake as part of overall dietary pattern on health status especially in children and adolescents.

Among the dairy types, particularly pronounced age trends were observed for LD and HSD w\%TD. The decreasing age trend for LD w\%TD with the highest intake rates among the youngest possibly could be attributed to the ongoing transition from the liquid infant formula to milk. 


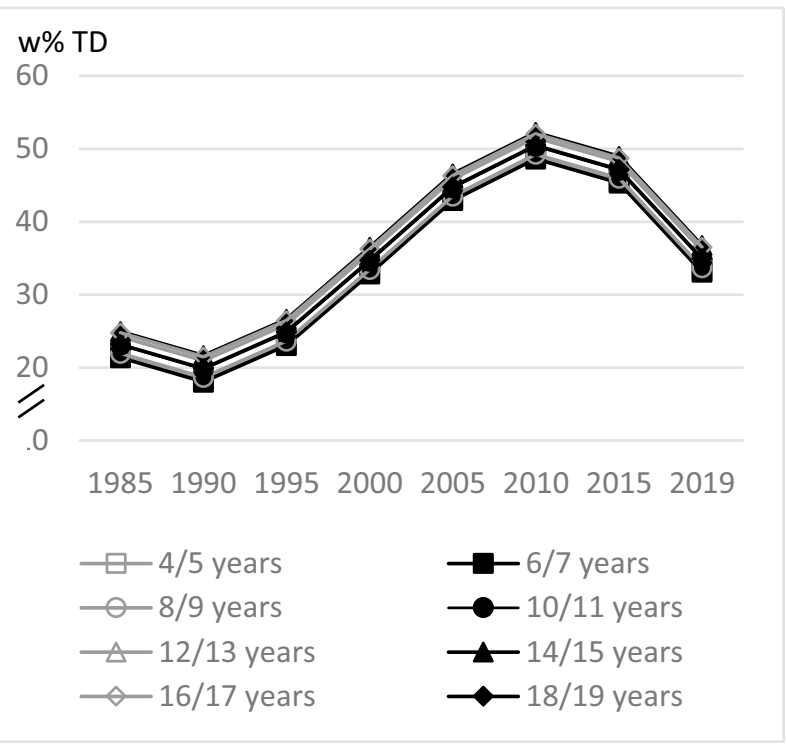

Fig. 2 Age and time trends in LFD w\%TD in boys and girls of 10,333 3-day-weighted dietary records of 648 male and 627 female DONALD study participants (3.5-18.5 years) between 1985 and 2019, predicted by polynomial mixed-effects regression models (see Table 3 )

The observed age trend in HSD w\%TD also with the highest intake rates among the youngest may be attributed to a higher sweet preference during childhood than late adolescence $[32,33]$.

In terms of time, our analysis showed the strongest trends for $\mathrm{LD}$ and FD w\%TD, with a decreasing LD and an increasing FD intake. In the above mentioned trend analysis of DONALD participants [14] which covered the period from
1986 to 2001, the reduced intake of LD was compensated by increased intake of solid dairy (i.e., to be eaten with spoons) whereas the overall dairy intake remained stable. In contrast, the present analysis showed that in the past decade, the shift from LD to solid dairy was associated with a general downward trend of TD intake. To our knowledge, there are no other trend analyses of LD or solid dairy, to which our results could be compared. Only in Canada, a descriptive comparison showed a reduction of the consumption of fluid milk in adults over the past two decades with a rise in the consumption of solid dairy foods, such as cheese and yogurt [30]. As in the case of sugar-sweetened beverages, liquid dairy are supposed to cause less satiation than solid dairy [11]. Overweight/obese children from the Avon Longitudinal Study consuming flavored milk had less favorable changes in body composition over time [34]. Whether this is due more to sugar content or consistency remains to be investigated. In contrast, FD w\% TD increased significantly over time. At the end of the observation period, fermented products even accounted for almost a third of TD intake. To our knowledge, no other studies analyzed age and time trends in FD intake. However, it should be noted, that various meta-analyses have indicated a benefit of consuming FD $[4,9,33,35,36]$. Hence, the observed increase in FD w\%TD among children and adolescents should be considered as a positive development.

We observed further time trends in LFD and HSD w\% TD. There was an initially strong increase of LFD w\% TD, similar to the aforementioned former evaluation of DONALD study data [14] from 1986 until 2001. Our analyses showed that this trend continued until 2010 and sharply declined afterwards. While in 2003 the majority

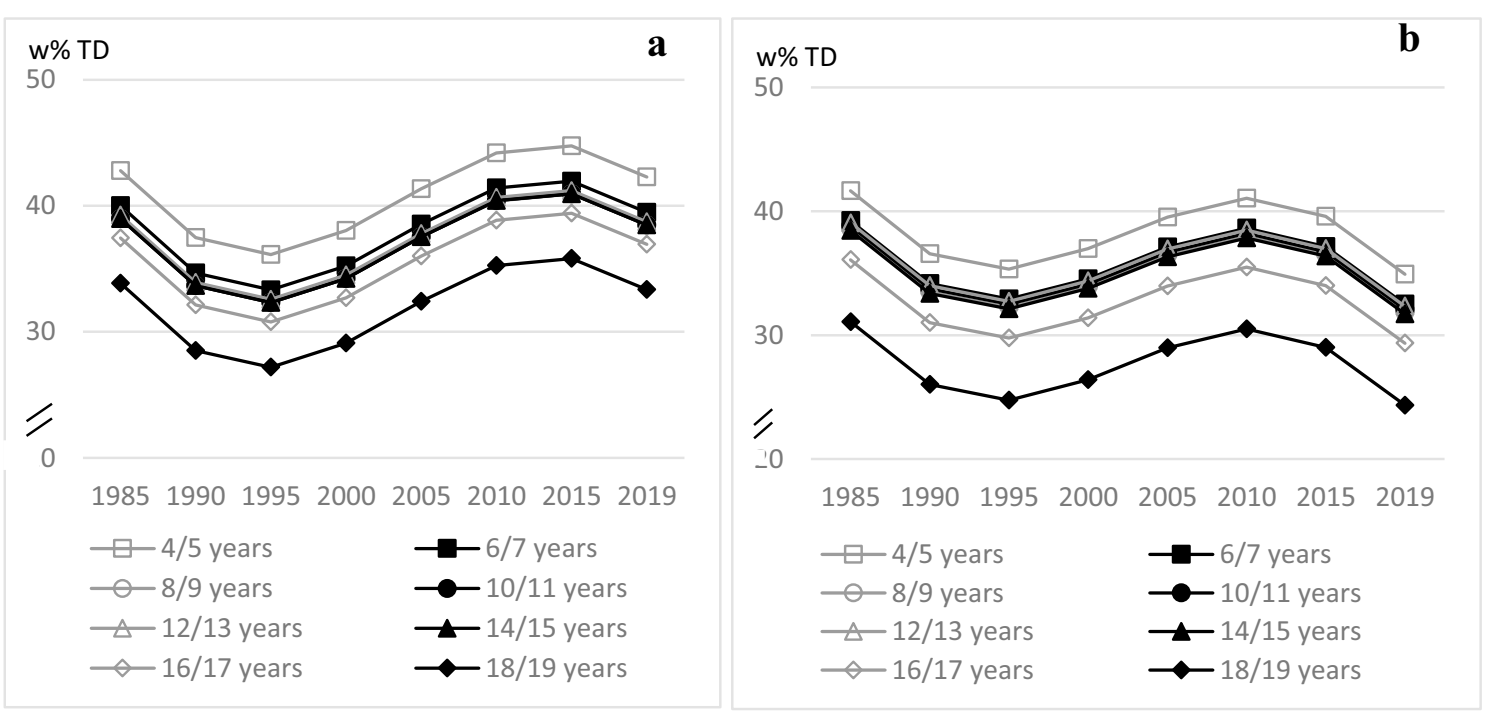

Fig. 3 Age and time trends in HSD w\% in boys (a) and in girls (b) of 10,333 3-day-weighted dietary records of 648 male and 627 female DONALD study participants (3.5-18.5 years) between 1985 and 2019, predicted by polynomial mixed-effects regression models (see Table 3 ) 


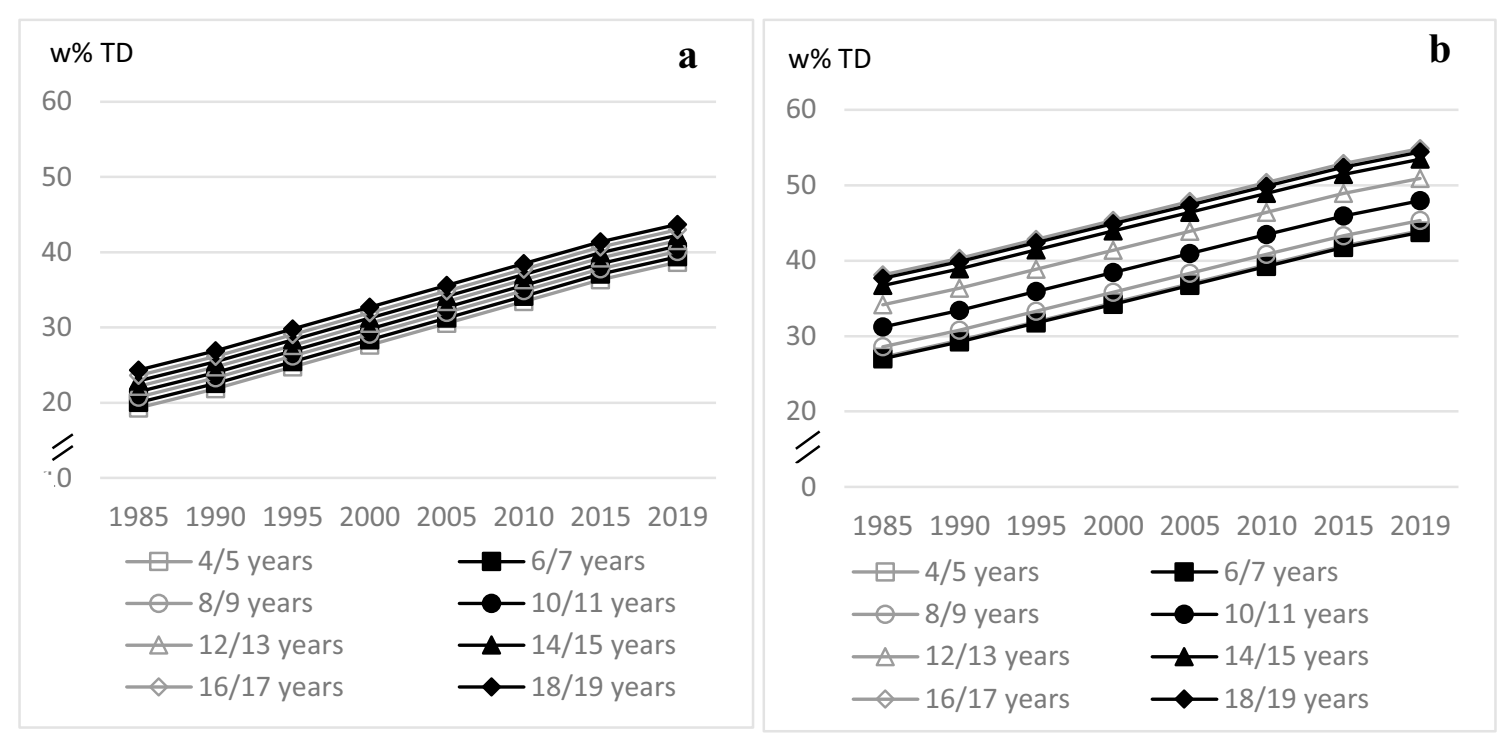

Fig. 4 Age and time trends in FD w\% in boys (a) and in girls (b) of 10,333 3-day-weighted dietary records of 648 male and 627 female DONALD study participants (3.5-18.5 years) between 1985 and 2019, predicted by polynomial mixed-effects regression models (see Table 3)

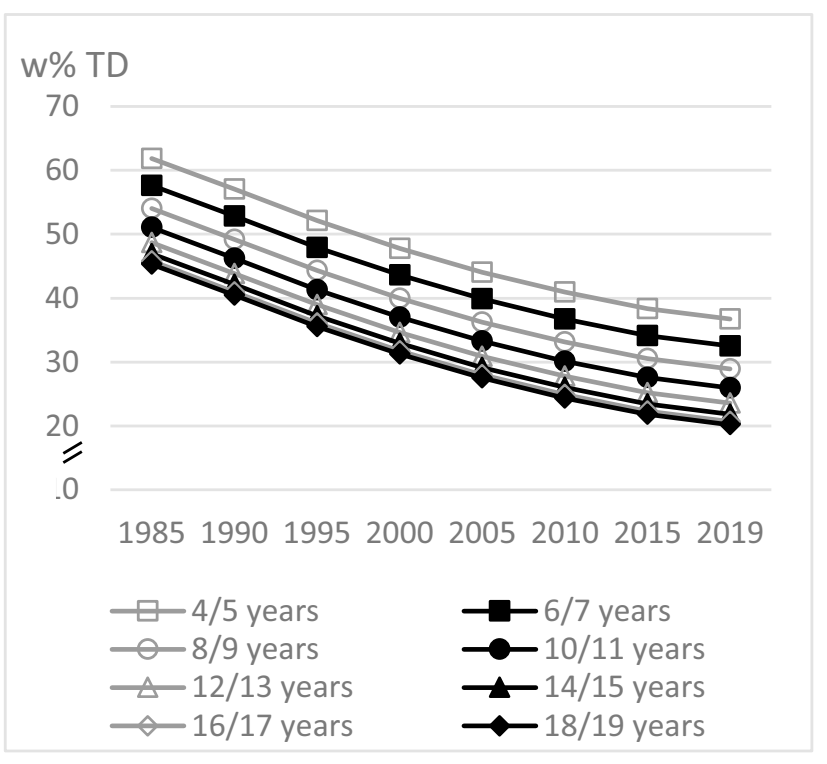

Fig. 5 Age and time trends in LD w\%TD in boys and girls of 10,333 3-day-weighted dietary records of 648 male and 627 female DONALD study participants (3.5-18.5 years) between 1985 and 2019, predicted by polynomial mixed-effects regression models (see Table 3 )

of food-based dietary guidelines in Europe recommended consumption of two to three servings of low-fat dairy products per day [37], these recommendations have been relativized in terms of fat content in some countries, such as Germany and Austria, as recent studies provide hints of potential health benefits from consumption of full-fat dairy products [38-42]. Currently, the effect of fat content in consumed dairy products on body weight in children is being studied in the Cow's Milk Fat Obesity pRevention Trial (CoMFORT) [43].

Similar to our time trend in HSD intake, a previous investigation of the DONALD study showed that free sugar intake from dairy increased slightly between 1985 and 2010 and decreased thereafter [7]. In contrast to these findings, HSD intake also decreased between 1985 and 1995. HSD intake accounted for about $19-32 \%$ of total dairy intake in the time period 2015-2019. There is a potential to reduce the amount of added sugar in dairy products by reformulation [44], in particular as natural lactose content results in a sweet taste of unfermented dairy. As the free sugar intake in Germany exceeded the limit of $10 \%$ of energy intake, a further reduction would be desirable [7, 45]. In addition, consumers should become aware that sweetened dairy products contribute to a relevant amount to free sugar intake [46] and encouraged to select unsweetened products. It should be noted that only industrially sweetened dairy has been taken into account in our study, whereas sugar or other sweeteners added in the household was not considered. Therefore, the overall contribution of sugar-sweetened dairy intake might be higher.

Some strengths and limitations of the DONALD study have to be discussed: The major strength of this study is the longitudinal design, which allows time and age trend analyses over a period of three decades in a large sample size using a large number of 3-day weighted dietary records. The continuously updated in-house nutrient database LEB$\mathrm{TAB}$ allows a consideration of different dairy types and their ingredients [18]. A limitation of the present study is the overrepresentation of families with a high socio-economic background in the collective of the DONALD study, which 
limits the generalizability of our results [17]. However, in the age group 14-18, our intake data are comparable to the results of the German National Food Consumption Study (Nationale Verzehrsstudie, NVS II) [47].

In addition, we cannot rule out the possibility of underreporting. However, our sensitivity analyses did not support the notion of bias from general underreporting, and the results for age and time trends were similar when we excluded underreported records.

\section{Conclusion}

Dairy consumption has been recommended as part of a healthy diet [48], as meta-analyses showed a significant inverse association of total dairy consumption with diabetes [49], Cancer [50] and Hypertension [51]. However, recent research suggests that the total dairy approach may be too simplistic, as dairy types may affect health in different ways $[38,52,53]$. In this article, we were able to show for the first time changes in the consumption patterns of dairy in children and adolescents over the past three decades, demonstrating for example, a switch from liquid to solid dairy with a simultaneous increase in fermented dairy. Further evaluations will investigate the health significance of these consumption patterns.

Supplementary Information The online version contains supplementary material available at https://doi.org/10.1007/s00394-021-02555-7.

\begin{abstract}
Acknowledgements The DONALD study is financially supported by the Ministry of Science and Research of North Rhine-Westphalia, Germany. The participation of all children and their families in the DONALD study is gratefully acknowledged. We also thank the DONALD staff for carrying out the anthropometric measurements, for administering the questionnaires, and for collecting and coding the dietary records.
\end{abstract}

Funding Open Access funding enabled and organized by Projekt DEAL.

\section{Declarations}

Conflict of interest On behalf of all the authors, the corresponding author states that there is no conflict of interest.

Open Access This article is licensed under a Creative Commons Attribution 4.0 International License, which permits use, sharing, adaptation, distribution and reproduction in any medium or format, as long as you give appropriate credit to the original author(s) and the source, provide a link to the Creative Commons licence, and indicate if changes were made. The images or other third party material in this article are included in the article's Creative Commons licence, unless indicated otherwise in a credit line to the material. If material is not included in the article's Creative Commons licence and your intended use is not permitted by statutory regulation or exceeds the permitted use, you will need to obtain permission directly from the copyright holder. To view a copy of this licence, visit http://creativecommons.org/licenses/by/4.0/.

\section{References}

1. Lu L, Xun P, Wan Y et al (2016) Long-term association between dairy consumption and risk of childhood obesity: a systematic review and meta-analysis of prospective cohort studies. Eur J Clin Nutr 70:414-423. https://doi.org/10.1038/ejen.2015.226

2. Huncharek M, Muscat J, Kupelnick B (2008) Impact of dairy products and dietary calcium on bone-mineral content in children: results of a meta-analysis. Bone 43:312-321. https://doi.org/10. 1016/j.bone.2008.02.022

3. Elwood PC, Pickering JE, Givens DI et al (2010) The consumption of milk and dairy foods and the incidence of vascular disease and diabetes: an overview of the evidence. Lipids 45:925-939. https:// doi.org/10.1007/s11745-010-3412-5

4. Gao D, Ning N, Wang C et al (2013) Dairy products consumption and risk of type 2 diabetes: systematic review and dose-response meta-analysis. PLoS One 8:e73965. https://doi.org/10.1371/journ al.pone. 0073965

5. Tong X, Dong J-Y, Wu Z-W et al (2011) Dairy consumption and risk of type 2 diabetes mellitus: a meta-analysis of cohort studies. Eur J Clin Nutr 65:1027-1031. https://doi.org/10.1038/ejcn.2011. 62

6. Aune D, Norat T, Romundstad P et al (2013) Dairy products and the risk of type 2 diabetes: a systematic review and dose-response meta-analysis of cohort studies. Am J Clin Nutr 98:1066-1083. https://doi.org/10.3945/ajen.113.059030

7. Perrar I, Schadow AM, Schmitting S et al (2019) Time and age trends in free sugar intake from food groups among children and adolescents between 1985 and 2016. Nutrients 12:20. https://doi. org/10.3390/nu12010020

8. Thorning TK, Bertram HC, Bonjour J-P et al (2017) Whole dairy matrix or single nutrients in assessment of health effects: current evidence and knowledge gaps. Am J Clin Nutr 105:1033-1045. https://doi.org/10.3945/ajen.116.151548

9. Sluijs I, Forouhi NG, Beulens JWJ et al (2012) The amount and type of dairy product intake and incident type 2 diabetes: results from the EPIC-InterAct Study. Am J Clin Nutr 96:382-390. https://doi.org/10.3945/ajcn.111.021907

10. Keast DR, Hill Gallant KM, Albertson AM et al (2015) Associations between yogurt, dairy, calcium, and vitamin D intake and obesity among U.S. children aged 8-18 years: NHANES, 20052008. Nutrients 7:1577-1593. https://doi.org/10.3390/nu7031577

11. Tsuchiya A, Almiron-Roig E, Lluch A et al (2006) Higher satiety ratings following yogurt consumption relative to fruit drink or dairy fruit drink. J Am Diet Assoc 106:550-557. https://doi.org/ 10.1016/j.jada.2006.01.004

12. PanHu ANFB (2011) Effects of carbohydrates on satiety: differences between liquid and solid food. Curr Opin Clin Nutr Metab Care 14:385-390. https://doi.org/10.1097/MCO.0b013e3283 $46 \mathrm{df} 36$

13. Santaliestra-Pasías AM, González-Gil EM, Pala V et al (2020) Predictive associations between lifestyle behaviours and dairy consumption: the IDEFICS study. Nutr Metab Cardiovasc Dis 30:514-522. https://doi.org/10.1016/j.numecd.2019.10.006

14. Alexy U, Kersting M (2003) Time trends in the consumption of dairy foods in German children and adolescents. Eur J Clin Nutr 57:1331-1337. https://doi.org/10.1038/sj.ejcn.1601696

15. Dietz WH (1994) Critical periods in childhood for the development of obesity. Am J Clin Nutr 59:955-959. https://doi.org/10. 1093/ajen/59.5.955 
16. Kroke A, Manz F, Kersting M et al (2004) The DONALD study. History, current status and future perspectives. Eur J Nutr 43:4554. https://doi.org/10.1007/s00394-004-0445-7

17. Buyken AE, Alexy U, Kersting M et al. Die DONALD Kohorte. Ein aktueller Überblick zu 25 Jahren Forschung im Rahmen der Dortmund Nutritional and Anthropometric Longitudinally Designed Study. Bundesgesundheitsblatt, Gesundheitsforschung, Gesundheitsschutz, pp 875-884

18. Sichert-Hellert W, Kersting M, Chahda C et al (2007) German food composition database for dietary evaluations in children and adolescents. J Food Compos Anal 20:63-70. https://doi.org/10. 1016/j.jfca.2006.05.004

19. Cole TJ, Bellizzi MC, Flegal KM et al (2000) Establishing a standard definition for child overweight and obesity worldwide: international survey. BMJ 320:1240-1243. https://doi.org/10. 1136/bmj.320.7244.1240

20. Cole TJ, Flegal KM, Nicholls D et al (2007) Body mass index cut offs to define thinness in children and adolescents: international survey. BMJ 335:194. https://doi.org/10.1136/bmj.39238.399444. 55

21. Foterek K, Hilbig A, Kersting M et al (2016) Age and time trends in the diet of young children: results of the DONALD study. Eur J Nutr 55:611-620. https://doi.org/10.1007/s00394-015-0881-6

22. Schofield WN (1985) Predicting basal metabolic rate, new standards and review of previous work. Hum Nutr Clin Nutr 39(Suppl 1):5-41

23. Sichert-Hellert W, Kersting M, Schöch G (1998) Underreporting of energy intake in 1 to 18 year old German children and adolescents. Z Ernahrungswiss 37:242-251. https://doi.org/10.1007/ s003940050023

24. Livingstone MB, Robson PJ (2000) Measurement of dietary intake in children. Proc Nutr Soc 59:279-293. https://doi.org/10.1017/ s0029665100000318

25. Black AE (2000) Critical evaluation of energy intake using the Goldberg cut-off for energy intake: basal metabolic rate. A practical guide to its calculation, use and limitations. Int J Obes Relat Metab Disord 24:1119-1130. https://doi.org/10.1038/sj.ijo.08013 76

26. Dror DK, Allen LH (2014) Dairy product intake in children and adolescents in developed countries: trends, nutritional contribution, and a review of association with health outcomes. Nutr Rev 72:68-81. https://doi.org/10.1111/nure.12078

27. Iglesia I, Intemann T, Miguel-Etayo P de et al (2020) Dairy consumption at snack meal occasions and the overall quality of diet during childhood. Prospective and cross-sectional analyses from the IDEFICS/I. Family cohort. Nutrients 12. https://doi.org/10. 3390/nu12030642

28. The European Commission's Science and Knowledge Service Food-Based Dietary Guidelines in Europe. https://ec.europa.eu/ $\mathrm{jrc/en/health-knowledge-gateway/promotion-prevention/nutrition/}$ food-based-dietary-guidelines. Accessed February 2021

29. Kersting M, Kalhoff H, Lücke T (2017) Von Nährstoffen zu Lebensmitteln und Mahlzeiten: das Konzept der Optimierten Mischkost für Kinder und Jugendliche in Deutschland. Aktuel Ernahrungsmed 42:304-315. https://doi.org/10.1055/s-0043-116499

30. Auclair O, Han Y, Burgos SA (2019) Consumption of milk and alternatives and their contribution to nutrient intakes among Canadian adults: evidence from the 2015 Canadian community health survey-nutrition. Nutrients 11:1948. https://doi.org/10.3390/ nu11081948

31. Willett W, Rockström J, Loken B et al (2019) Food in the anthropocene: the EAT-Lancet Commission on healthy diets from sustainable food systems. Lancet 393:447-492. https://doi.org/10. 1016/S0140-6736(18)31788-4
32. Ventura AK, Mennella JA (2011) Innate and learned preferences for sweet taste during childhood. Curr Opin Clin Nutr Metab Care 14:379-384. https://doi.org/10.1097/MCO.0b013e328346df65

33. de Graaf C, Zandstra EH (1999) Sweetness intensity and pleasantness in children, adolescents, and adults. Physiol Behav 67:513520. https://doi.org/10.1016/S0031-9384(99)00090-6

34. Noel SE, Ness AR, Northstone K et al (2013) Associations between flavored milk consumption and changes in weight and body composition over time: differences among normal and overweight children. Eur J Clin Nutr 67:295-300. https://doi.org/10. 1038/ejcn.2012.123

35. Pfeuffer M, Watzl B (2018) Nutrition and health aspects of milk and dairy products and their ingredients. Ernährungs Umschau 65:22-33. https://doi.org/10.4455/eu.2018.006

36. Romaguera D, Ängquist L, Du H et al (2011) Food composition of the diet in relation to changes in waist circumference adjusted for body mass index. PLoS One 6:e23384. https://doi.org/10.1371/ journal.pone.0023384

37. Nutrition and Food Security Programme (2003) Food based dietary guidelines in the WHO European Region: EUR/03/5045414 E79832, Denmark. https://apps.who.int/iris/handle/10665/107490. Accessed February 2021

38. Astrup A, Geiker NRW, Magkos F (2019) Effects of full-fat and fermented dairy products on cardiometabolic disease: food is more than the sum of its parts. Adv Nutr 10:924S-930S. https://doi.org/ 10.1093/advances/nmz069

39. Kratz M, Baars T, Guyenet S (2013) The relationship between high-fat dairy consumption and obesity, cardiovascular, and metabolic disease. Eur J Nutr 52:1-24. https://doi.org/10.1007/ s00394-012-0418-1

40. O'Sullivan TA, Schmidt KA, Kratz M (2020) Whole-fat or reduced-fat dairy product intake, adiposity, and cardiometabolic health in children: a systematic review. Adv Nutr. https://doi.org/ 10.1093/advances/nmaa011

41. Thorning TK, Raben A, Tholstrup T et al (2016) Milk and dairy products: good or bad for human health? An assessment of the totality of scientific evidence. Food Nutr Res 60:32527. https:// doi.org/10.3402/fnr.v60.32527

42. Bechthold A (2018) Vollwertig essen und trinken nach den 10 Regeln der DGE, 1. Auflage. Deutsche Gesellschaft für Ernährung e. V. (DGE), Bonn. ISBN 9783887492595

43. Vanderhout SM, Aglipay M, Birken C et al (2020) Cow's milk fat obesity prevention trial (CoMFORT): a primary care embedded randomised controlled trial protocol to determine the effect of cow's milk fat on child adiposity. BMJ Open 10:e035241. https:// doi.org/10.1136/bmjopen-2019-035241

44. McCain HR, Kaliappan S, Drake MA (2018) Invited review: sugar reduction in dairy products. J Dairy Sci 101:8619-8640. https:// doi.org/10.3168/jds.2017-14347

45. Graffe MIM, Pala V, de Henauw S et al (2020) Dietary sources of free sugars in the diet of European children: the IDEFICS study. Eur J Nutr 59:979-989. https://doi.org/10.1007/ s00394-019-01957-y

46. Fidler Mis N, Braegger C, Bronsky J et al (2017) Sugar in infants, children and adolescents: a position paper of the European Society for paediatric gastroenterology, hepatology and nutrition committee on nutrition. J Pediatr Gastroenterol Nutr 65:681-696. https:// doi.org/10.1097/MPG.0000000000001733

47. Max Rubner-Institut, Bundesforschungsinstitut für Ernährung und Lebensmittel (2008) Nationale Verzehrsstudie II: Ergebnisbericht Teil 2. https://www.mri.bund.de/fileadmin/MRI/Institute/EV/ NVSII_Abschlussbericht_Teil_2.pdf. Accessed September 2020

48. Guo J, Givens DI, Astrup A et al (2019) The impact of dairy products in the development of type 2 diabetes: where does the evidence stand in 2019? Adv Nutr 10:1066-1075. https://doi.org/ 10.1093/advances/nmz050 
49. Schwingshackl L, Hoffmann G, Lampousi A-M et al (2017) Food groups and risk of type 2 diabetes mellitus: a systematic review and meta-analysis of prospective studies. Eur J Epidemiol 32:363375. https://doi.org/10.1007/s10654-017-0246-y

50. Schwingshackl L, Schwedhelm C, Galbete C et al (2017) Adherence to Mediterranean diet and risk of cancer: an updated systematic review and meta-analysis. Nutrients 9:1063. https://doi.org/ 10.3390/nu9101063

51. Schwingshackl L, Schwedhelm C, Hoffmann G et al (2017) Food groups and risk of hypertension: a systematic review and dose-response meta-analysis of prospective studies. Adv Nutr 8:793-803. https://doi.org/10.3945/an.117.017178

52. Schmidt JM, Kjølbæk L, Jensen KJ et al (2020) Influence of type of dairy matrix micro- and macrostructure on in vitro lipid digestion. Food Funct 11:4960-4972. https://doi.org/10.1039/d0fo0 $0785 \mathrm{~d}$

53. Turgeon SL, Brisson G (2020) Symposium review: the dairy matrix-bioaccessibility and bioavailability of nutrients and physiological effects. J Dairy Sci 103:6727-6736. https://doi.org/10. 3168/jds.2019-17308 